\title{
Human Embryonic Stem Cells in the Treatment of Patients With Duchenne Muscular Dystrophy: A Case Series
}

\author{
Geeta Shroff
}

\begin{abstract}
Duchenne muscular dystrophy (DMD), an X-linked disorder, occurs due to mutation, deletion or duplication of the DMD gene which encodes the protein dystropin. It is estimated to affect 1 in 3,300 boys. The disease progression leads to muscles necrosis. In cases discussed in this article, five patients with DMD were treated with human embryonic stem cells (hESCs). All patients showed stability and mild improvement clinically like the ability to walk, stand, and sit, improved breathing capacity, increased body weight, improved hand functions and improved muscle strength. A remarkable reduction occurred in the creatine phosphokinase (CPK) levels of all the five patients without further deterioration. In conclusion, hESCs might become an effective therapeutic option for DMD in the future. More clinical data are needed to gather evidences supporting the use of hESC in the treatment of DMD.
\end{abstract}

Keywords: Human embryonic stem cell; hESC therapy; Duchenne muscular dystrophy; Genetic disorder

\section{Introduction}

Duchenne muscular dystrophy (DMD), an X-linked disorder, occurs due to mutation, deletion or duplication of the DMD gene which encodes the protein dystropin [1,2], present on the cytoplasmic surface of sarcolemma (plasma membrane) of the skeletal muscle [3]. Absence of dystropin at the sarcolemma leads to loss of dystropin associated proteins leading to the muscle fibers becoming prone to mechanical stresses $[4,5]$.

The World Health Organization (WHO) estimated that DMD affects 1 in 3,300 boys [6]. Despite advances in medical technology, there is still no cure for DMD. The treatment options for DMD are only aimed at preserving and improving the function and strength of patients [7]. Nowadays, researchers are targeting cell-based therapies that might alter the progres-

Manuscript accepted for publication March 31, 2015

Nutech Mediworld, New Delhi, India. Email: geetashroff@hotmail.com

doi: http://dx.doi.org/10.14740/jnr326w sion of DMD [8-11].

The present study evaluated the therapeutic efficacy of human embryonic stem cells (hESCs) in the treatment of five patients with DMD.

After hESCs therapy, there were improvements in patient's condition who suffered from neurodegenerative disorders like cerebral palsy and cortical visual impairment $[12,13]$.

\section{Case Reports}

\section{Methods}

hESCs are cultured and maintained as per our proprietary inhouse patented technology in a Good Manufacturing Practices (GMP), Good Laboratory Practices (GLP) and Good Tissue Practices (GTP) certified laboratory at Nutech Mediworld (patent WO 2007/141657A PCT/1B 2007, published December 13, 2007). The evidence for the use of hESCs at Nutech Mediworld has also been submitted in written and accepted at House of Lords, Regenerative Medicine, Science and Technology Committee [14]. The details of the technique have been described elsewhere [12]. The cell lines are free of animal product and are chromosomally stable.

The stem cell therapy was given in treatment phases followed by a gap phase in between. In first phase, T1 (12 weeks), $0.25 \mathrm{~mL}$ hESCs were administered through intramuscular (IM) route twice daily (to prime the body), $1 \mathrm{~mL}$ were administered intravenously (IV) twice a week (to allow the cells to home at the injured site) and $1-5 \mathrm{~mL} \mathrm{hESCs}$ were administered every 7 days by caudal routes (to introduce the stem cells for local action). Additionally, IM injections were also given over the affected muscle groups including calves, thighs, back, biceps, deltoid, triceps and quadriceps. Deep muscle injections were also given twice a week. The successive treatment phases T2, T3 (each of 4 weeks) also followed the same dose regime as $\mathrm{T} 1$ and these phases are required to add more cells to the body so as to allow more repair and regeneration. The gap phase between these treatment periods is $3-4$ months so that the injected cells can develop into a mature cell. The duration of gap phase was determined keeping in view the time taken for development of complete organs (14 - 16 weeks) in human fetus [15].

Patients were diagnosed with DMD elsewhere and ap- 
proached our facility for treatment. All the patients provided written informed consent prior to start of the treatment. The patients had to undergo a detailed examination by the doctors and the rehabilitation team before, during and after each treatment cycle. All the patients had their condition video graphed before, during and after the treatment periods. The biochemical investigations were done before the start of the treatment and then at regular intervals. In-house physicians and nurses carefully observed all the patients for antigenic or anaphylactic responses. The patients were also reviewed by an external physician. The observations documented by the various teams were then examined by a separate team of doctors not involved with patient care.

\section{Case 1}

A 16-year-old boy was admitted to Nutech Mediworld on April 26, 2010 with complaints of loss of balance, scoliosis, inability to stand or walk, sit straight, and turn on sides and was wheelchair bound since 2005 . The patient's history revealed that he had difficulty in playing/participating in physical activities since the age of 5 years. With time the patient's condition deteriorated further with difficulty in climbing stairs, standing, walking with frequent falls. At the age of 6 years, he was diagnosed with DMD. On examination, the patient had a poor sitting balance, was not able to move his lower limb (LL), had minimum movement in arms, could move his hands but with poor control and got mild breathlessness after doing exercises. He also had flexion deformity of bilateral $(\mathrm{B} / \mathrm{L})$ elbows, ankles and knees, diminished reflexes, pigeon chest, scoliosis curvature, body posture bent at hip right $(\mathrm{Rt})>$ left (Lt), no hand grip, decreased use of hand for daily activities, impaired voluntary control of upper limb (UL) and no shoulder shrugging.

Electromyography (EMG) of the patient showed that he was suffering from muscle disease. Diagnosis of DMD was confirmed with elevated creatine phosphokinase (CPK, 3,307 IU/L) and CPK-MB (81 IU/L). DNA analysis showed partial dystrophin gene deletion spanning exons 5 to 7 .

At Nutech Mediworld, the patient was treated with hESC as a primary therapy in addition to extensive physiotherapy and occupational therapy. Following the treatment with hESC, an overall improvement was observed in the patient. The patient had an improved sitting posture (without any support), hand muscle control, muscle bulk and coral muscle strength. A reduction in elbows and knees tightness was observed. The patient was able to stand on full calipers and walker without any external support, swing and kick the Swiss ball, could shrug his shoulders, feed himself and turn on sides with minimal support. The gene deletion test is yet to be done.

His CPK level decreased from 3,307 IU/L (before treatment) to $54 \mathrm{IU} / \mathrm{L}$ (at last follow-up visit on May 16, 2013). Presently, the patient is 20 years old and is keeping well.

\section{Case 2}

A 13-year-old male was admitted to Nutech Mediworld on
April 12, 2006 with complaints of muscle weakness in all the muscle groups (proximal > distal), stiffness in wrist and fingers, tightness of all joints, impaired fine hand functions, difficulty in holding pen and poor hand grip. The patient was unable to stand or walk, had poor sitting balance and was wheelchair bound since 2 years. The patient was apparently well until the age of 4 years, when he was first noticed to have weakness of body which gradually increased in severity. He was diagnosed with DMD in 1998 and underwent treatment but no improvement was observed.

On examination, the patient had decreased deep tendon reflex, poor hand grip, flexion deformity in limbs, B/L foot equines, impaired pinch strength and fine hand function, muscle wasting of forearm, thenar and hypothenar muscles, early fatigability with poor stamina and scoliosis towards right affecting the posture. The patient had restricted range of motion and was unable to stand even with the support.

The CPK levels of the patient were elevated (1,775 IU/L), the muscle biopsy showed features of muscular dystrophy and immunochemistry for dystrophin 2 and 3 was negative while dystrophin 1 was reduced and patchy.

At Nutech Mediworld, the patient underwent hESC therapy as a primary treatment with extensive physiotherapy and occupational therapy. The patient was also given calcium supplement (500 mg, OD), iron tablets (40 mg, OD) and vitamin B-12 tablets (OD).

Following the treatment with the hESC therapy, an improvement was observed in muscle mass, knee and elbow tightness, active standing balance, trunk balance and stamina. The body weight of the patient increased, he was able to stand erect with half knee caliper and frame for approximately 15 min and tried to take step, was able to sit without support and kick the ball. His shoulder raising was also better and he was able to lift his shoulder to throw the ball, write with good pinch grasp, had improved hand functions with good hand grip and was able to feed himself with his own hands. His CPK level decreased during the treatment period from 1,775 IU/L (prior to treatment on April 12, 2006) to $572 \mathrm{IU} / \mathrm{L}$ (after treatment on May 27, 2013). The patient is surviving and is 21 years old now.

\section{Case 3}

A 6-year-old patient was admitted to Nutech Mediworld on June 19, 2006 with complaints of muscle weakness (proximal $>$ distal), decreased stamina, difficulty in standing and inability to walk properly. When he was 3 years old his parents recognized that he had difficulty in getting up without support. He was diagnosed with DMD in 2002.

On examination, he had diminished reflexes, calf muscles hypertrophy, scoliosis, B/L foot drop, B/L knee buckling, pigeon chest, waddling gait and $\mathrm{B} / \mathrm{L}$ hip in external rotation. On investigation, CPK was elevated (6,922 IU/L), DNA analysis revealed a deletion in the dystrophin gene of exon 44, muscle biopsy showed feature of muscular dystrophy and immunochemistry for dystrophin 2 and 3 was negative while dystrophin 1 was reduced and patchy. After the confirmation of DMD, the patient was treated with hESC and extensive physiotherapy. 
He showed few signs of improvement such as slight reduction in scoliosis, was able to walk using ankle-foot-orthosis (AFO) and walker, had reduced foot drop and the muscle tone was maintained.

Patient discontinued further treatment session for a year. He again revisited Nutech Mediworld on May 12, 2011 with complaints of gross motor deficit in all four limbs with severe muscle weakness, no power in proximal muscle groups, not able to walk, not able to use ULs, bed ridden, wheelchair bound and poor sitting balance. He was unable to close eyes tightly, puff up cheeks and feed himself, had B/L foot drop with tendo-achilles tightness and low breathing capacity.

His blood investigations were performed again which showed that his CPK total was 1,887 IU/L (decreased after receiving hESC therapy) and CPK-MB was 27.6 IU/L.

He was again treated with hESC therapy as the first line therapy in addition to extensive physiotherapy and occupational therapy. Following the treatment, the patient showed an improvement in sitting balance, standing balance with trunkhip-knee-ankle-foot orthoses (THKAFO) and walker, breathing capacity and shoulder strength. His $\mathrm{B} / \mathrm{L}$ tendo-achilles tightness reduced and hand grip improved.

On the return of the patient for next session of hESC therapy his disease progression was slower and he was suffering from gross weakness of all muscle groups, slurring of speech with nasal tone and swallowing difficulty. He was unable to walk and stand, do daily routine activities, had increase in scoliosis and poor sitting balance with brace.

Overall, the patient showed no significant improvement. Only the progression of disease slowed down. Continued reduction was noticed in the CPK level following the sessions of hESC therapy which reduced from $6,922 \mathrm{IU} / \mathrm{L}$ to $412 \mathrm{IU} / \mathrm{L}$. The patient is now 14 years old.

\section{Case 4}

A 14-year-old patient was admitted to Nutech Mediworld on June 11, 2004 with complaints of muscle weakness, flexion deformity in $\mathrm{B} / \mathrm{L}$ elbows and knees, inability to turn on sides and lift his arms or legs without support. Patient history revealed that he started walking at the age of one and a half year. He attended yoga classes at the age of 4 years where his yoga teacher noticed that he could not stretch his legs apart. His calf muscles were also found to bulge.

At the age of 5 years, the patient was diagnosed with DMD and confirmed with DNA analysis. He received all the traditional treatments for DMD but showed no signs of improvement. By the age of 9 years he had weakness in B/L LL slowly progressing and affecting UL too. The proximal muscles were affected more than the distal muscles in both UL and LL. The patient had difficulty in getting up from sitting position, climbing stairs and his sitting balance was also affected due to muscle weakness. He was wheelchair bound since 13 years of age.

On investigation, his CPK was noted to be 2,343 IU/L and examination showed muscle weakness (proximal $>$ distal), contractures on $\mathrm{B} / \mathrm{L}$ knee, poor sitting balance, muscle wasting, hypertrophy of calf and tongue muscles, poor handgrip (cannot hold a pen or glass) and inability to stand or walk.
Patient was treated with hESC as primary treatment in addition to extensive physiotherapy and occupational therapy. After the treatment, patient showed improvement in signs of disease such as no deterioration, reduction in muscle wasting with improved muscle tone. His weight increased, was able to move his LL at will and able to sit straight without support, had improved hand grip (could hold a glass of water and drink on his own if his elbow and upper arm is supported) and could write holding a pen. His CPK levels also showed remarkable decrease from 2,343 IU/L in 2004 to 1,220 IU/L in 2009. Now, the patient is 19 years old.

\section{Case 5}

A 21-year-old male patient was admitted to Nutech Mediworld in July 2008 with complaints of muscle weakness (proximal > distal), inability to stand or walk even with support, difficulty in turning himself, impaired hand functions and wheelchair bound.

Patient was apparently well till 5 years of age, when his parents first noticed that he had slight balancing difficulty, standing up with support of his knees and was lagging behind the other kids in activities like running or climbing stairs. He was diagnosed with DMD at the age of 6 years. Patient underwent traditional treatment but his condition was progressively deteriorating.

On examination, the patient had poor stamina, restricted range of motion and stiffness of all joints, poor hand grip, unable to stand or walk without support, had poor sitting balance and his activity of daily living was affected.

On investigation, CPK levels were 1,198 IU/L, muscle biopsy showed features of muscular dystrophy, immunohistochemistry of dystrophin 1, 2 and 3, and sarcoglycans- $\alpha, \beta, \gamma$ and $\delta$ showed normal staining pattern. Features were those of dysferlinopathy.

Patient was treated with hESc and extensive physiotherapy initially for 12 weeks. After the treatment, his condition was stable. Improvements were found in stamina, hand movements and hand grip. He was able to sit without support for almost 20 min, could stand with calipers without support of walker and tooke steps in parallel bars and had reduction in stiffness in joint.

On second visit in 2009, patient was given hESC therapy. At the time of discharge patient showed improvement in sitting and standing balance, increase in stamina, hand grip and LL strength. He was able to take backward steps in parallel bars, stand with full calipers and without any support for longer time and range of motion maintained in the joints.

On the third visit, patient had complaints of weakness of shoulder, both arms and hand muscles, muscle wasting of hand muscles, slight difficulty in breathing, impairment of hand activities, tightness of back and B/L knees, scoliosis posture (towards right) and his CPK total was decreased to 1,210 IU/L.

On receiving the treatment, tightness of knees and back reduced and weight gain occurred. He was able to stand with full caliper without external support and maintain balance, could walk forward with help of walker on calipers and walk backwards without any external help on calipers and breathing 


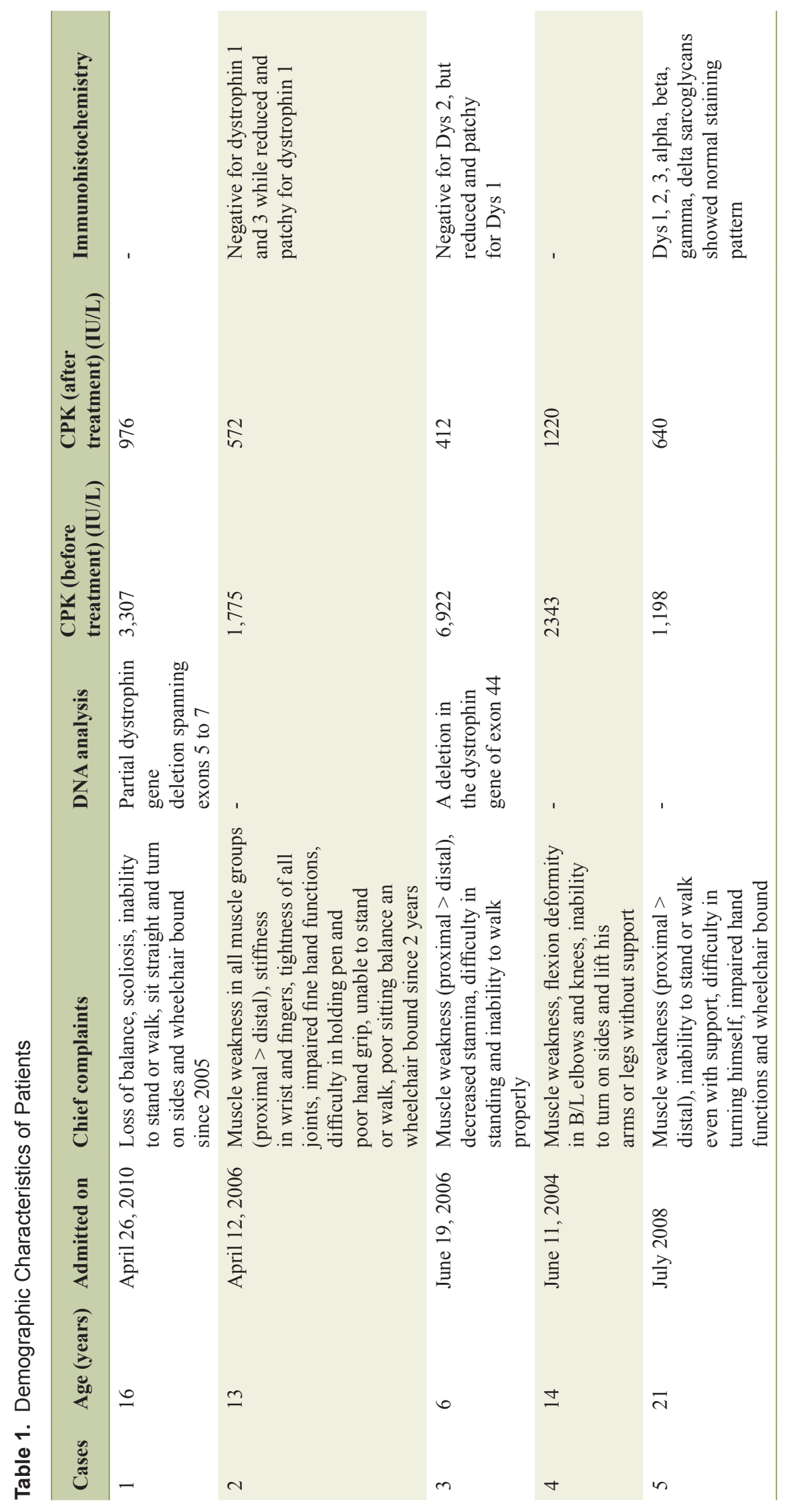


improved. He also showed improvement in shoulder strength, wrist muscle strength, overall power and the use of hand increased.

On fourth visit, patient complained of muscle weakness, poor sitting balance, low breathing capacity, knees and back tightness and poor hand grip.

Patient was treated with hESC for 4 weeks in addition to physiotherapy and occupational therapy as secondary treatment. Improvement was noticed in breathing capacity with improved chest expansion, hand grip, slight reduction occurred in knee and back tightness and the patient was able to stand without support.

The patient suffered from the disease even after the treatment but the progression of disease slowed down.

Overall, patient showed improvement in stamina, hand movements, hand grip, shoulder strength, wrist muscle strength and LL strength. He was able to sit without support for almost half an hour, his breathing capacity improved, weight gain occurred, range of motion maintained in the joints, able to walk with help of walker on calipers and walk backwards without any external help on calipers.

His CPK levels showed remarkable reduction from 1,198 IU/L (prior to start of the treatment) to $640 \mathrm{IU} / \mathrm{L}$ (at the last follow-up in March 2014). This patient died due to an anaphylactic reaction to an antibiotic drug taken in another hospital.

\section{Discussion}

Progression of DMD is characterized by muscle weakness, muscle necrosis, respiratory insufficiency, cardiomyopathy, wheelchair boundness by the age of 12 years and death of the affected individuals before the age of 20 years [16-18]. The medical management for DMD patients only delays the outcome of disease, thus the deterioration of patients condition continues to occur [7, 19]. However, in our study patients survived beyond the age of 20 years after being treated with hESCs that too without any usual deterioration.

New management approaches for DMD such as exon skipping, gene therapy and cellular therapy seem better that might alter the progression of DMD and improve the patient survival. However, use of exon skipping and gene therapy still presents several challenges that need to be addressed before their use in the treatment of DMD $[20,21]$.

Different types of stem cells have been recognized to be capable of muscle regeneration including the satellite cells (SCs) [22], bone marrow stem cells [11], muscle side population (SP) cells [8], muscle-derived stem cells [9], mesoangioblasts [23], embryonic stem cells [24] and induced pluripotent stem cells (iPSCs) [25]. An in vitro study assessed the therapeutic role of embryonic stem (ES) cells in the treatment of autosomal dominant forms of muscular dystrophy. Pax3induced ES-derived myogenic progenitors were transplanted into Frg1 mice which showed that these cells have significant capability of engraftment and muscle regeneration [26]. Barberi et al investigated that hESCs have potential to generate skeletal myoblasts and multipotent mesenchymal precursor's in vitro. Skeletal myoblasts were then transplanted into severe combined immunodeficiency (SCID)/Beige mice and were found to remain viable following the transplantation [24].

Transplanted stem cells are known to repair and regenerate tissues through various paracrine mechanisms including angiogenesis, stimulation of satellite stem cells and stimulation of various growth factors [27]. hESCs used in our study might have acted in the same manner.

Our study used in-house cultured hESCs. The cell line has been created from a single fertilized ovum 24 - $48 \mathrm{~h}$ after fertilization when the conceptus is assumed to have reached the 4-16 cell stage. Media used in culturing the cell lines are free from animal contaminants and cells of animal origin.

Our study is the first to assess the therapeutic efficacy of hESC in the treatment of patients with DMD. Our patients showed improvement following the treatment with hESCs. All patients showed stability and mild improvement clinically like the ability to walk, stand and sit, breathing capacity, increased body weight, improved hand functions and improved muscle strength. All of them had a remarkable reduction in CPK levels after the treatment (Table 1). However, more studies and clinical trials are needed to gather the evidences supporting the use of hESCs in the treatment of DMD.

\section{Acknowledgement}

The author acknowledges the patients, doctors and staff of Nutech Mediworld. The author also acknowledges Knowledge Isotopes Pvt. Ltd. (http://www.knowledgeisotopes.com) for writing support.

\section{Conflict of Interest}

The author declares no conflict of interest.

\section{References}

1. Peddareddygari LR, Pillai BH, Nochlin D, Sharer LR, Grewal RP. Phenotype-genotype analysis of dystrophinopathy caused by duplication mutation in Dystrophin gene in an African patient. Afr Health Sci. 2011;11(4):607-609.

2. Koenig M, Hoffman EP, Bertelson CJ, Monaco AP, Feener C, Kunkel LM. Complete cloning of the Duchenne muscular dystrophy (DMD) cDNA and preliminary genomic organization of the DMD gene in normal and affected individuals. Cell. 1987;50(3):509-517.

3. Zubrzycka-Gaarn EE, Bulman DE, Karpati G, Burghes AH, Belfall B, Klamut HJ, Talbot J, et al. The Duchenne muscular dystrophy gene product is localized in sarcolemma of human skeletal muscle. Nature. 1988;333(6172):466-469.

4. Matsumura K, Tome FM, Ionasescu V, Ervasti JM, Anderson RD, Romero NB, Simon D, et al. Deficiency of dystrophin-associated proteins in Duchenne muscular dystrophy patients lacking $\mathrm{COOH}$-terminal domains of dystrophin. J Clin Invest. 1993;92(2):866-871.

5. Petrof BJ. The molecular basis of activity-induced muscle injury in Duchenne muscular dystrophy. Mol Cell Bio- 
chem. 1998;179(1-2):111-123.

6. WHO. Coming together to combat rare diseases. Available From: http://wwwwhoint/bulletin/volumes/90/6/12020612/en/; accessed on 8 July, 2014.

7. Bushby K, Finkel R, Birnkrant DJ, Case LE, Clemens PR, Cripe L, Kaul A, et al. Diagnosis and management of Duchenne muscular dystrophy, part 1: diagnosis, and pharmacological and psychosocial management. Lancet Neurol. 2010;9(1):77-93.

8. Doyle MJ, Zhou S, Tanaka KK, Pisconti A, Farina NH, Sorrentino BP, Olwin BB. Abcg2 labels multiple cell types in skeletal muscle and participates in muscle regeneration. J Cell Biol. 2011;195(1):147-163.

9. Lee JY, Qu-Petersen Z, Cao B, Kimura S, Jankowski R, Cummins J, Usas A, et al. Clonal isolation of muscle-derived cells capable of enhancing muscle regeneration and bone healing. J Cell Biol. 2000;150(5):1085-1100.

10. Skuk D, Goulet M, Roy B, Chapdelaine P, Bouchard JP, Roy R, Dugre FJ, et al. Dystrophin expression in muscles of duchenne muscular dystrophy patients after high-density injections of normal myogenic cells. J Neuropathol Exp Neurol. 2006;65(4):371-386.

11. Ferrari G, Cusella-De Angelis G, Coletta M, Paolucci E, Stornaiuolo A, Cossu G, Mavilio F. Muscle regeneration by bone marrow-derived myogenic progenitors. Science. 1998;279(5356):1528-1530.

12. Shroff G, Das L. Human Embryonic Stem Cell Therapy in Cerebral Palsy Children with Cortical Visual Impairment: A Case Series of 40 Patients. J Cell Sci Ther. 2015;5:189.

13. Shroff G, Gupta A, Barthakur J. Therapeutic potential of human embryonic stem cell transplantation in patients with cerebral palsy. J Transl Med. 2014;12(1):318.

14. House of Lords SATSC. Available from: http://www.parliament.uk/documents/lords-committees/science-technology/RegenerativeMedicine/RegenMed.pdf. Accessed on September 26, 2014.

15. MedlinePlus. Available from: http://www.nlm.nih.gov/ medlineplus/ency/article/002398.htm. Accessed on September 1, 2014.

16. Emery AE. Population frequencies of inherited neuromuscular diseases--a world survey. Neuromuscul Disord. 1991;1(1):19-29.
17. Emery AEH. Duchenne muscular dystrophy. Oxford Monographs on Medical Genetics, Revised Ed. 15. England, Oxford: Oxford University Press; 1988.

18. Moser H. Duchenne muscular dystrophy: pathogenetic aspects and genetic prevention. Hum Genet. 1984;66(1):1740.

19. Bushby K, Finkel R, Birnkrant DJ, Case LE, Clemens PR, Cripe L, Kaul A, et al. Diagnosis and management of Duchenne muscular dystrophy, part 2: implementation of multidisciplinary care. Lancet Neurol. 2010;9(2):177189.

20. Arechavala-Gomeza V, Anthony K, Morgan J, Muntoni F. Antisense oligonucleotide-mediated exon skipping for Duchenne muscular dystrophy: progress and challenges. Curr Gene Ther. 2012;12(3):152-160.

21. Konieczny P, Swiderski K, Chamberlain JS. Gene and cell-mediated therapies for muscular dystrophy. Muscle Nerve. 2013;47(5):649-663.

22. Schultz E. Satellite cell proliferative compartments in growing skeletal muscles. Dev Biol. 1996;175(1):84-94.

23. Minasi MG, Riminucci M, De Angelis L, Borello U, Berarducci B, Innocenzi A, Caprioli A, et al. The mesoangioblast: a multipotent, self-renewing cell that originates from the dorsal aorta and differentiates into most mesodermal tissues. Development. 2002;129(11):27732783.

24. Barberi T, Bradbury M, Dincer Z, Panagiotakos G, Socci ND, Studer L. Derivation of engraftable skeletal myoblasts from human embryonic stem cells. Nat Med. 2007;13(5):642-648.

25. Darabi R, Arpke RW, Irion S, Dimos JT, Grskovic M, Kyba M, Perlingeiro RC. Human ES- and iPS-derived myogenic progenitors restore DYSTROPHIN and improve contractility upon transplantation in dystrophic mice. Cell Stem Cell. 2012;10(5):610-619.

26. Darabi R, Baik J, Clee M, Kyba M, Tupler R, Perlingeiro RC. Engraftment of embryonic stem cell-derived myogenic progenitors in a dominant model of muscular dystrophy. Exp Neurol. 2009;220(1):212-216.

27. Gnecchi M, Zhang Z, Ni A, Dzau VJ. Paracrine mechanisms in adult stem cell signaling and therapy. Circ Res. 2008;103(11):1204-1219. 